\title{
Growth Factors for Clinical-Scale Expansion of Human Articular Chondrocytes: Relevance for Automated Bioreactor Systems
}

\author{
SILVIA-ELENA FRANCIOLI, B.Sc., ${ }^{1}$ IVAN MARTIN, Ph.D., ${ }^{1}$ CHRISTINA-PRISKA SIE, B.Sc., \\ RUPERT HAGG, Ph.D., ${ }^{2}$ ROBERTO TOMMASINI, Ph.D., ${ }^{2}$ CHRISTIAN CANDRIAN, M.D., ${ }^{1}$ \\ MICHAEL HEBERER, M.D., ${ }^{1}$ and ANDREA BARBERO, Ph.D. ${ }^{1}$
}

\begin{abstract}
The expansion of chondrocytes in automated bioreactors for clinical use requires that a relevant number of cells be generated, starting from variable initial seeding densities in one passage and using autologous serum. We investigated whether the growth factor combination transforming growth factor beta 1/fibroblast growth factor 2/platelet-derived growth factor BB (TFP), recently shown to enhance the proliferation capacity of human articular chondrocytes (HACs), allows the efficiency of chondrocyte use to be increased at different seeding densities and percentages of human serum (HS). HACs were seeded at 1,000, 5,000 , and 10,000 cells $/ \mathrm{cm}^{2}$ in medium containing $10 \%$ fetal bovine serum or 10,000 cells $/ \mathrm{cm}^{2}$ with $1 \%, 5 \%$, or $10 \% \mathrm{HS}$. The chondrogenic capacity of post-expanded HACs was then assessed in pellet cultures. Expansion with TFP allowed a sufficient number of HACs to be obtained in one passage even at the lowest seeding density and HS percentage and variability in cartilage-forming capacity of HACs expanded under the different conditions to be reduced. Instead, larger variations and insufficient yields were found in the absence of TFP. By allowing large numbers of cells to be obtained, starting from a wide range of initial seeding densities and HS percentages, the use of TFP may represent a viable solution for the efficient expansion of HACs and addresses constraints of automated clinical bioreactor systems.
\end{abstract}

\section{INTRODUCTION}

A RTICULAR CARTILAGE has a limited capacity for selfrepair, and if left untreated, cartilage defects can lead to the early onset of osteoarthritic degenerative changes. Promising approaches to induce cartilage repair are based on the implantation of autologous chondrocytes directly after expansion ${ }^{1}$ or after loading and culture on specific scaffolds. ${ }^{2-5}$ The manufacture of cell-based products for cartilage repair typically requires shipment of a small cartilage biopsy to Good Manufacturing Practice (GMP) facilities, where chondrocytes are isolated, expanded in culture flasks, and shipped back to the healthcare center. These procedures are, however, associated with complicated logistics and, because of the pre- dominance of manual handling steps, to limited standardization and ultimately high costs.

The use of bioreactors within the hospital or healthcare center for automated culture of autologous cells would eliminate logistical issues of transferring specimens between locations, reduce the need for large and expensive GMP facilities, and minimize operator handling, with the final possible result of simplifying, reducing the cost, and increasing the standardization of chondrocyte-based cartilage repair techniques. One example of this, Autologous Clinical Tissue Engineering System (ACTES), under development by Millenium Biologix (www.millenium-biologix.com), is a closed bioreactor system aimed at fully automating the processes of cartilage biopsy digestion, chondrocyte expansion, rinsing,

\footnotetext{
${ }^{1}$ Institute for Surgical Research and Hospital Management, University Hospital Basel, Basel, Switzerland.

${ }^{2}$ Millenium Biologix AG, Zürich-Schlieren, Switzerland.
} 
and concentration in a defined medium volume. ${ }^{6}$ However, in a bioreactor system like ACTES, cells have to be expanded in only one passage, and because of the fixed area of the culture surface and the variable size of cartilage biopsies, the initial cell seeding densities may be highly variable between production batches. Moreover, the system should use human autologous serum at low percentages, to avoid use of animal-derived factors and to reduce the dependence of the culture on a non-standardized factor such as autologous serum. With these constraints, the bioreactor system should yield at least 12 million chondrocytes, because typical autologous chondrocyte implantation is indicated to treat cartilage defects up to $12 \mathrm{~cm}^{2}$ in size by injection of at least 1 million cells per $\mathrm{cm}^{2}$ defect. $^{7}$

With the ultimate goal of defining suitable operating conditions for systems like ACTES, in the present study we aimed at determining whether a clinically relevant number $(\geq 12$ million) of human articular chondrocytes (HACs) can be generated in 1 passage starting from variable initial seeding densities and using low percentages of human serum, assuming a culture surface area of $250 \mathrm{~cm}^{2}$, currently in use in the ACTES system. Specific growth factors, namely transforming growth factor beta 1 (TGF $\beta-1)$, fibroblast growth factor 2 (FGF-2), and platelet-derived growth factor type $\mathrm{BB}$ (PDGF-BB) (TFP), previously shown to increase the proliferation efficiency of $\mathrm{HACs},{ }^{8,9}$ were tested to reduce the variability in the yield of HACs under the different conditions. Because the quality of HAC expansion is related not only to the number but also to the cartilag-forming capacity of the expanded cells, HACs grown under the different experimental conditions were assessed in a micromass pellet culture model typically used to investigate the chondrogenic capacity of various cells types. ${ }^{10,11}$

\section{MATERIALS AND METHODS}

\section{Human serum}

Pools of human serum (HS) were purchased by Blutspendezentrum SRK Bern AG, and serum from 3 healthy donors was isolated from Blutzentrum, University Hospital Basel, Basel, Switzerland. The sera were aliquoted and stored at $-20^{\circ} \mathrm{C}$ until ready for use. Heat inactivation of the sera was not performed.

\section{Cartilage sample collection and cell isolation}

Full-thickness human articular cartilage biopsies were obtained postmortem (within $24 \mathrm{~h}$ after death) from the lateral condyle of knee joints of 5 individuals (mean age 42.7, range 27-61) with no history of joint disease, after informed consent by relatives and in accordance with the local ethics committee of University Hospital Basel, Switzerland. The biopsies used, although they were not derived from a traumatic joint, would be relevant for our target clinical application (e.g., treatment of cartilage injuries), considering the es- tablished similarity between chondrocytes surrounding a cartilage defect or from normal cartilage. ${ }^{12}$ Cartilage tissues were minced and then digested with $0.15 \%$ type II collagenase $(10 \mathrm{~mL}$ solution/g tissue, $300 \mathrm{U} / \mathrm{mg}$, Worthington Biochemical Corporation, Lakewood, NJ) for $22 \mathrm{~h}$, and the isolated chondrocytes were then seeded and expanded as described below.

\section{Cell expansion}

Cell seeding at different densities. Freshly isolated HACs were seeded at $1,000,5,000$ or 10,000 cells $/ \mathrm{cm}^{2}$ with Dulbecco's modified Eagle medium (DMEM) containing 4.5 $\mathrm{mg} / \mathrm{mL}$ D-glucose, $0.1 \mathrm{mM}$ nonessential amino acids, $1 \mathrm{mM}$ sodium pyruvate, $100 \mathrm{mM} \mathrm{N}$-2-hydroxyethylpiperazine- $\mathrm{N}^{\prime}$ 2-ethanesulfonic acid buffer, $100 \mathrm{U} / \mathrm{mL}$ penicillin, $100 \mu \mathrm{g} /$ $\mathrm{mL}$ streptomycin, and $0.29 \mathrm{mg} / \mathrm{mL}$ L-glutamate (basic medium) supplemented with $10 \%$ fetal bovine serum (FBS) without (CTR) or with the addition of growth factors $(1 \mathrm{ng} / \mathrm{mL}$ TGF $\beta 1,5 \mathrm{ng} / \mathrm{mL}$ FGF-2, and $10 \mathrm{ng} / \mathrm{mL}$ PDGF-BB) (TFP) ${ }^{13}$ and expanded in monolayer for 1 passage in a humidified $37^{\circ} \mathrm{C} / 5 \%$ carbon dioxide $\left(\mathrm{CO}_{2}\right)$ incubator. Medium was changed twice a week.

The densities 1,000 cells $/ \mathrm{cm}^{2}$ and 5,000 cells $/ \mathrm{cm}^{2}$ were used considering the size of a cartilage biopsy usually provided from patients undergoing autologous chondrocyte implantation (100-500 mg), ${ }^{7}$ a normal yield after tissue digestion $\left(2.6 \times 10^{6} \text { cells/g }\right)^{14}$ and the available cell expansion surface in ACTES system $\left(250 \mathrm{~cm}^{2}\right),{ }^{6}$ whereas 10,000 cells/ $\mathrm{cm}^{2}$ was considered to be a standard cell-seeding density. ${ }^{13,15}$

When HACs reached confluence, they were rinsed with phosphate buffered saline, detached by treatment with $0.3 \%$ type II collagenase, followed by $0.05 \%$ trypsin $/ 0.53 \mathrm{mM}$ ethylenediamine tetraacetic acid (EDTA), counted, and used to generate pellets as described below.

Use of different percentages of human serum. Freshly isolated HACs were seeded at 10,000 cells $/ \mathrm{cm}^{2}$ with basic medium supplemented with $1 \%, 5 \%$, or $10 \%$ HS without or with supplementation of the growth factor combination TFP and expanded in monolayer for 1 passage in a humidified $37^{\circ} \mathrm{C} / 5 \% \mathrm{CO}_{2}$ incubator. Cells from 1 additional individual (male, 51 years old) were also cultured with $1 \%, 5 \%$, or $10 \%$ serum obtained from 3 different donors.

\section{Three-dimensional pellet cultures}

To assess the quality of the expanded chondrocytes, HACs were induced to re-differentiate in pellet cultures as previously described. ${ }^{8}$ Briefly, HAC were suspended in basic medium supplemented with ITS +1 (Sigma Chemical, St. Louis, MO; i.e., $10 \mu \mathrm{g} / \mathrm{mL}$ insulin, $5.5 \mathrm{mg} / \mathrm{mL}$ transferrin, $5 \mathrm{ng} / \mathrm{mL}$ selenium, $0.5 \mathrm{mg} / \mathrm{mL}$ bovine serum albumin, $4.7 \mathrm{mg} / \mathrm{mL}$ linoleic acid), $0.1 \mathrm{mM}$ ascorbic acid 2-phosphate, $1.25 \mathrm{mg} / \mathrm{mL}$ human serum albumin, $10^{-7} \mathrm{M}$ dexamethasone and $10 \mathrm{ng} / \mathrm{mL}$ TGF- $\beta 1$ (chondrogenic medium). Aliquots of $5 \times 10^{5}$ cells $/ 0.5 \mathrm{~mL}$ were centrifuged at $250 \mathrm{~g}$ for $5 \mathrm{~min}$ in 
1.5-mL polypropylene conical tubes (Sarstedt, Nümbrecht, Germany) to form pellets, which were placed onto an orbital shaker (Bioblock Scientific, Frenkendor, Switzerland) at $30 \mathrm{rpm}$. Pellets were cultured for 2 weeks, with medium changes twice per week, and subsequently processed for histological, immunohistochemical, and biochemical analysis as described below. Each analysis was performed independently on at least 2 entire pellets for each primary culture and expansion condition.

\section{Analytical methods}

Proliferation rate. Proliferation rate was calculated as the ratio of $\log _{2}\left(\mathrm{~N} / \mathrm{N}_{0}\right)$ to $\mathrm{T}$, where $\mathrm{N}_{0}$ and $\mathrm{N}$ are the numbers of cells respectively at the beginning and end of the expansion phase, $\log _{2}\left(\mathrm{~N} / \mathrm{N}_{0}\right)$ is the number of cell doublings, and $\mathrm{T}$ is the time required for the expansion.

Histological and Immunohistochemical analysis. Pellets were fixed in $4 \%$ formalin for $24 \mathrm{~h}$ at $4{ }^{\circ} \mathrm{C}$, embedded in paraffin, cross-sectioned ( $5 \mu \mathrm{m}$ thick), and stained with Safranin $\mathrm{O}$ for sulfated glycosaminoglycans (GAGs). Sections were also processed for immunohistochemistry to visualize collagen type II (II-II6B3, Hybridoma Bank, University of Iowa, Iowa City, IA), as previously described. ${ }^{16}$

Biochemical analysis. Pellets were digested with protease $\mathrm{K}(0.5 \mathrm{~mL}$ of $1 \mathrm{mg} / \mathrm{mL}$ protease $\mathrm{K}$ in $50 \mathrm{mM}$ Tris with $1 \mathrm{mM}$ EDTA, $1 \mathrm{mM}$ iodoacetamide, and $10 \mu \mathrm{g} / \mathrm{mL}$ pepstatin-A) for $15 \mathrm{~h}$ at $56^{\circ} \mathrm{C}$, as previously described. ${ }^{17} \mathrm{GAG}$ amounts were measured spectrophotometrically using dimethylmethylene blue, ${ }^{18}$ with chondroitin sulfate as a standard, and normalized to the deoxyribonucleic acid (DNA) amounts, measured spectrofluorometrically using the CYQuant cell proliferation assay Kit (Molecular Probes, Eugene, OR) and with calf thymus DNA as a standard. GAG contents are reported as $\mu \mathrm{g}$ $\mathrm{GAG} / \mu \mathrm{g}$ DNA.

Statistical analysis. All values are presented as means \pm standard deviation of measurements from 4 to 5 independent experiments (with cells from the 4-5 different individuals). The coefficient of variation (standard deviation as a per- centage of the mean), was used to assess the variability of a certain parameter under different culture conditions. Differences between experimental groups were assessed using Mann-Whitney tests and considered statistically significant at $p<0.05$.

\section{RESULTS}

\section{Cell seeding at different densities}

Cell proliferation. This set of experiments was performed using medium containing $10 \%$ FBS.

In CTR medium, HACs seeded at 10,000 and 5,000 cells/ $\mathrm{cm}^{2}$ proliferated at comparable rates. Cells reached confluence within 15 to 19 days of culture and underwent a similar number of doublings (2.2 and 2.9, respectively) (Table 1). Instead, HACs seeded at 1,000 cells $/ \mathrm{cm}^{2}$ required more than 3 weeks to reach confluence, and during this time they underwent 2.2-fold more doublings than cells seeded at the highest density (Table 1). In general, a decrease in cell density paralleled enhanced HAC expansion; the total cell doublings were 4.8, 2.9, and 2.2 for cells seeded at the densities of 1,000, 5,000 and 10,000 cells $/ \mathrm{cm}^{2}$, respectively (Table 1).

In medium containing growth factors (TFP medium), at any seeding density, chondrocytes proliferated at a remarkably and significantly higher rate (up to 3.5-fold), reached confluence in a shorter time (up to 2.0-fold) and underwent more doublings (up to 1.9-fold) than HACs cultured in CTR medium (Table 1). As observed for cells cultured in CTR medium, doublings of HACs expanded with TFP increased by decreasing seeding density $(7.6,5.4$, and 3.9 for the seeding densities of 1,000, 5,000 and 10,000 cells $/ \mathrm{cm}^{2}$, respectively). Expansion with TFP resulted in reduced variability in the proliferation rates of HACs seeded at the different seeding densities, with the coefficient of variation decreasing from 27.5 to 14.6 .

We then used the doublings measured under the different conditions to estimate the number of HACs that would be obtained if chondrocytes were seeded in the culture surface of the ACTES system (equal to $250 \mathrm{~cm}^{2}$ ). The required number for clinical-scale expansion (12 million cells) would not

Table 1. Expansion of Human Articular Chondrocytes (HAC) in Relation to Seeding Density

\begin{tabular}{|c|c|c|c|c|c|c|c|c|c|}
\hline & \multicolumn{3}{|c|}{$1000 \mathrm{cells} / \mathrm{cm}^{2}$} & \multicolumn{3}{|c|}{$5000 \mathrm{cells} / \mathrm{cm}^{2}$} & \multicolumn{3}{|c|}{$10000 \mathrm{cells} / \mathrm{cm}^{2}$} \\
\hline & Doublings & $\begin{array}{l}\text { Expansion } \\
\text { time (days) }\end{array}$ & $\begin{array}{l}\text { Proliferation } \\
\text { rate }\end{array}$ & Doublings & $\begin{array}{c}\text { Expansion } \\
\text { time (days) }\end{array}$ & $\begin{array}{c}\text { Proliferation } \\
\text { rate }\end{array}$ & Doublings & $\begin{array}{l}\text { Expansion } \\
\text { time (days) }\end{array}$ & $\begin{array}{c}\text { Proliferation } \\
\text { rate }\end{array}$ \\
\hline CTR & $4.8 \pm 0.4^{*}$ & $24.3 \pm 3.1^{*}$ & $0.20 \pm 0.04^{*}$ & $2.9 \pm 0.8$ & $18.7 \pm 2.1$ & $0.17 \pm 0.05$ & $2.2 \pm 0.6$ & $15.0 \pm 2.6$ & $0.15 \pm 0.04$ \\
\hline TFP & $7.6 \pm 0.8^{* \circ}$ & $12.0 \pm 1.6^{* \circ}$ & $0.64 \pm 0.05^{* \circ}$ & $5.4 \pm 0.7 *^{\circ}$ & $10.6 \pm 1.8^{* \circ}$ & $0.51 \pm 0.06^{\circ}$ & $3.9 \pm 0.6^{\circ}$ & $7.6 \pm 0.5^{\circ}$ & $0.52 \pm 0.07^{\circ}$ \\
\hline TFP/CTR & 1.6 & 0.5 & 3.2 & 1.9 & 0.6 & 3.0 & 1.8 & 0.5 & 3.5 \\
\hline
\end{tabular}

HAC were seeded in monolayer at different densities in medium containing $10 \%$ fetal bovine serum and cultured without growth factors (CTR) or with transforming growth factor beta 1, fibroblast growth factor 2, and platelet-derived growth factor type BB (TFP) for 1 passage. For the calculation of the parameter see the Materials and Methods section. Results are means \pm standard deviations of values from 4 to 5 independent donor cells populations. $* p<0.05$ from 10,000 cells $/ \mathrm{cm}^{2} ;{ }^{\circ} p<0.05$ from CTR. 
be reached for any of the seeding densities in CTR medium, whereas expansion with TFP would yield more than 40 millions of cells for each seeding density condition (Fig. 1A).

Chondrogenic capacity. Because not only the number of cells obtained after expansion, but also their quality, is a clinically relevant issue, we evaluated the chondrogenic capacity of cells expanded in the different conditions in a pellet culture model. HACs seeded at 10,000 and 5,000 cells $/ \mathrm{cm}^{2}$ produced tissues that stained similarly with Safranin O, whereas cells seeded at 1,000 cells $/ \mathrm{cm}^{2}$ generated pellets with a lower staining intensity (Fig. 2A). Biochemical analysis of the pellets confirm this trend, although because of the large donor-to-donor variability, no statistically significant difference in the GAG contents of the generated tissues could be measured between the experimental conditions. Expansion with TFP reduced the variability in the GAG contents of pellets produced by cells seeded at different densities histologically and biochemically, with the coefficient of variation for the GAG/DNA contents decreasing from $37.5 \%$ to $24.5 \%$ (Fig. 2B).

\section{Cell expansion using different percentages of $H S$}

Cell proliferation. This set of experiments was performed using an initial seeding density of 10,000 cells $/ \mathrm{cm}^{2}$.

A

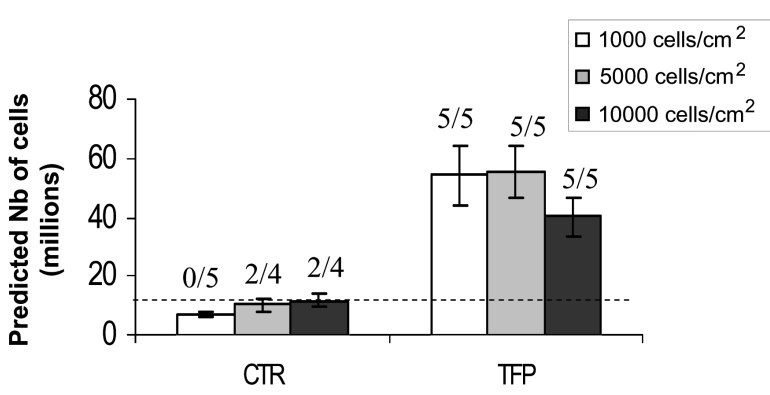

B

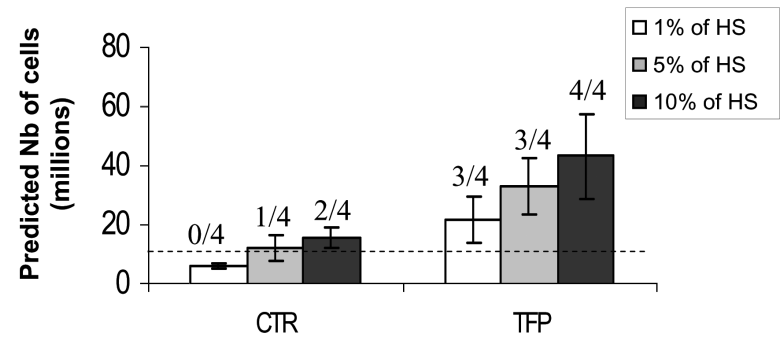

FIG. 1. Predicted number of human articular chondrocytes (HACs) that would be obtained after expansion in a culture surface comparable to that of Autologous Clinical Tissue Engineering System $\left(250 \mathrm{~cm}^{2}\right)$ under different conditions of initial seeding densities (A) or percentage of human serum (HS) (B). Results are means \pm standard deviations of values from 4 to 5 independent donor cells. Fractions over each bar represent the ratio of cultures that reached a minimum of 12 million to total cultures analyzed.
In CTR medium, HACs cultured with $10 \%$ and 5\% HS proliferated at comparable rates. Cells reached confluence within 9.5 to 10.5 days of culture and underwent a similar number of doublings (2.5 and 2.1, respectively) (Table 2). However, cells expanded with $1 \%$ HS required more time to reach confluence (1.4-fold) and underwent fewer doublings (2.1-fold) than chondrocytes cultured with $10 \%$ HS (Table 2). Chondrocytes displayed a higher proliferation rate overall (1.9-fold) when cultured with 10\% HS than with $10 \%$ FBS (see Table 1 and 2).

In TFP medium, HACs cultured at any HS percentage proliferated at a higher rate than those cultured in CTR medium, although because of large donor-to-donor variability, statistical significance was established only for the lowest serum concentration. At $1 \%$ HS, TFP-expanded chondrocytes reached confluence in a shorter time (1.6-fold) and underwent more doublings (2.3-fold) than CTR-expanded cells (Table 2). Expansion with TFP resulted in less variability in the proliferation rates of HACs cultured with the different

\section{A}
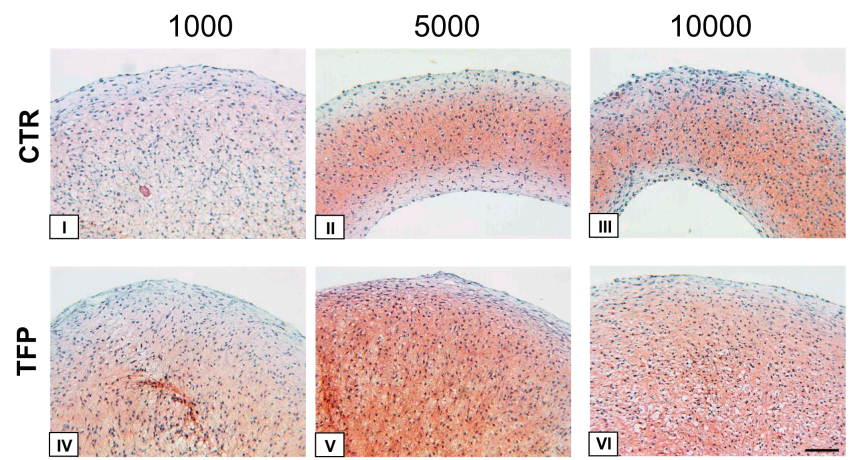

B

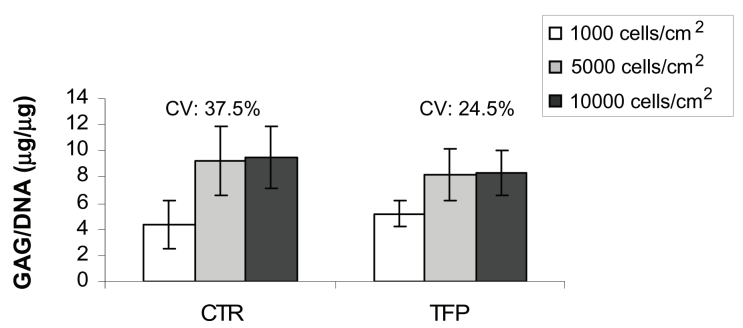

FIG. 2. Glycosaminoglycan (GAG) accumulation in pellets generated by human articular chondrocytes (HACs) after expansion under different initial seeding density conditions. (A) Safranin O staining of representative pellets generated by HACs seeded at 1,000 (I and IV), 5,000 (II and V), or 10,000 (III and VI) cells $/ \mathrm{cm}^{2}$ and expanded in CTR (I, II, and III) or TFP (IV, V, and VI) medium. Bar $=100 \mu \mathrm{m}$. (B) GAG content normalized to the amount of deoxyribonucleic acid (DNA) (GAG/DNA) in the pellets generated by HACs expanded under the different conditions. Results are means \pm standard deviations of values from 4 to 5 independent donor cell populations. Coefficients of variation (CVs) over each bar are the standard deviations (as \% of the mean) of the GAG contents measured at the different cell-seeding densities. Color images available online at www.liebertpub.com/ten. 
Table 2. Expansion of Human Articular Chondrocytes (HACs) in Relation to Human Serum (HS) Percentage

\begin{tabular}{|c|c|c|c|c|c|c|c|c|c|}
\hline & \multicolumn{3}{|c|}{$1 \% H S$} & \multicolumn{3}{|c|}{$5 \% H S$} & \multicolumn{3}{|c|}{$10 \% \mathrm{HS}$} \\
\hline & Doublings & $\begin{array}{l}\text { Expansion } \\
\text { time (days) }\end{array}$ & $\begin{array}{c}\text { Proliferation } \\
\text { rate }\end{array}$ & Doublings & $\begin{array}{l}\text { Expansion } \\
\text { time (days) }\end{array}$ & $\begin{array}{c}\text { Proliferation } \\
\text { rate }\end{array}$ & Doublings & $\begin{array}{l}\text { Expansion } \\
\text { time (days) }\end{array}$ & $\begin{array}{c}\text { Proliferation } \\
\text { rate }\end{array}$ \\
\hline CTR & $1.2 \pm 0.5^{*}$ & $13.5 \pm 2.6^{*}$ & $0.12 \pm 0.1 *$ & $2.1 \pm 0.9$ & $10.5 \pm 3.0$ & $0.23 \pm 0.2$ & $2.5 \pm 0.6$ & $9.5 \pm 2.1$ & $0.29 \pm 0.1$ \\
\hline TFP & $2.7 \pm 1.2^{\circ}$ & $8.5 \pm 1.3^{\circ}$ & $0.34 \pm 0.2^{\circ}$ & $3.5 \pm 1.1$ & $8.5 \pm 1.3$ & $0.42 \pm 0.2$ & $3.9 \pm 0.9$ & $8.2 \pm 1.5$ & $0.49 \pm 0.16$ \\
\hline TFP/CTR & 2.3 & 0.6 & 2.8 & 1.7 & 0.8 & 1.8 & 1.6 & 0.9 & 1.7 \\
\hline
\end{tabular}

HACs were seeded in monolayer at 10,000 cells $/ \mathrm{cm}^{2}$ and cultured with different HS concentrations in medium without growth factors (CTR) or with transforming growth factor beta 1, fibroblast growth factor 2, and platelet-derived growth factor type BB (TFP) for 1 passage. For the calculation of the parameter, see the Materials and Methods section. Results are means \pm standard deviations of values from 4 independent donor cell populations. ${ }^{*} p<0.05$ from $10 \% \mathrm{HS} ;{ }^{\circ} p<0.05$ from CTR.

concentrations of HS, with the coefficient of variation decreasing from 45.3 to 22.2 .

In CTR medium, cells cultured with $1 \%$ HS would not yield the required number of cells (12 million) if cultured under the same conditions in the culture surface of the ACTES system $\left(250 \mathrm{~cm}^{2}\right)$, whereas in TFP medium, more then 20 million chondrocytes would be generated for each HS percentage (Fig. 1B).

Chondrogenic capacity. HACs expanded in CTR medium with $10 \%$ and $5 \%$ HS produced tissues similarly stained with Safranin O, whereas cells expanded with $1 \%$ HS generated pellets with a lower staining intensity (Fig. 3A). Biochemical analysis of the pellets confirmed this trend, but because of the large donor-to-donor variability, no statistically significant difference in the GAG contents of the generated tissues could be established between the experimental conditions. Expansion with TFP reduced variability in the GAG contents of pellets produced by cells cultured with different HS percentages, with coefficient of variation decreasing from $11.6 \%$ to $4.4 \%$ (Fig. 3B). Tissues that contained large amounts of GAG generally contained higher amounts of collagen type II protein, as assessed using immunohistochemical staining (Fig. 3C).

To determine whether HS from different donors could promote cell proliferation and re-differentiation capacity differently, chondrocytes from 1 additional cartilage biopsy were expanded in TFP medium with serum obtained from 3 different donors and then cultured in pellets. For each HS percentage condition used $(1 \%, 5 \%$, and $10 \%)$, cells proliferated at similar rates (coefficient of variation $<6.0$ ). However, a greater percentage of HS used during the expansion resulted in enhanced variability in the GAG contents of pellets generated by cells expanded with serum from different donors, with the coefficients of variation of $4.7,19.5$, and 46.1 for $1 \%, 5 \%$, and $10 \% \mathrm{HS}$, respectively (Fig. 4).

\section{DISCUSSION}

With the final goal of validating culture conditions for clinical-scale expansion of HACs, we investigated the pro- liferation capacity of HACs cultured starting from a wide range of initial seeding densities $(1,000,5,000$, and 10,000 cells $\left./ \mathrm{cm}^{2}\right)$ and HS percentages $(1 \%, 5 \%$, and $10 \%)$ in medium not supplemented and supplemented with growth factors. We found that expansion with CTR medium was not reproducible and did not yield a clinically relevant number of chondrocytes ( $\geq 12$ millions) at each seeding density condition and at the lowest percentage of HS. Using TFP medium, instead, proliferation capacity was strongly enhanced such that 22 to 55 million chondrocytes could be generated in the different experimental conditions tested. Moreover, medium supplementation with TFP reduced variability in proliferation and cartilage-forming capacity of cells expanded under the different experimental conditions.

In clinical practice, the dimension of a cartilage biopsy and therefore the number of chondrocytes available for ex vivo expansion will vary from donor to donor. Therefore, having the constraint of a fixed surface area, have initially evaluated the effect of seeding density on HAC proliferation capacity. To the best of our knowledge, this is the first study evaluating the growth capacity of articular chondrocytes of human origin at different initial seeding densities. Similar investigations have been performed using chondrocytes from nonarticular sites ${ }^{19,20}$ or of animal origin. ${ }^{21}$ Our results indicate that HACs seeded at decreasing densities proliferated in CTR medium with greater rates, such that a maximum number of population doublings (4.8) was measured for HACs seeded at $1,000 \mathrm{cells} / \mathrm{cm}^{2}$. Mandl et al. observed a similar relationship between initial seeding density and proliferation capacity with human auricular chondrocytes. ${ }^{20}$ The authors reported that, using a density of 3,500 or 7,500 cells $/ \mathrm{cm}^{2}$, a 20 -fold increase in cell number was reached between passage 2 and 3 for most donors. We have demonstrated that human articular chondrocytes seeded at 1,000 cells $/ \mathrm{cm}^{2}$ undergo almost 8 doublings (corresponding to more than a 250 -fold increase in cell number) in less than 2 weeks in just 1 passage while maintaining their differentiation capacity, but only in the presence of TFP. Thus, the use of TFP during HAC expansion allows a clinically relevant number of cells to be obtained also if initially seeded at low densities (and therefore starting from a cartilage biopsy of small size), reduces the time required for cell expansion, and reduces the 


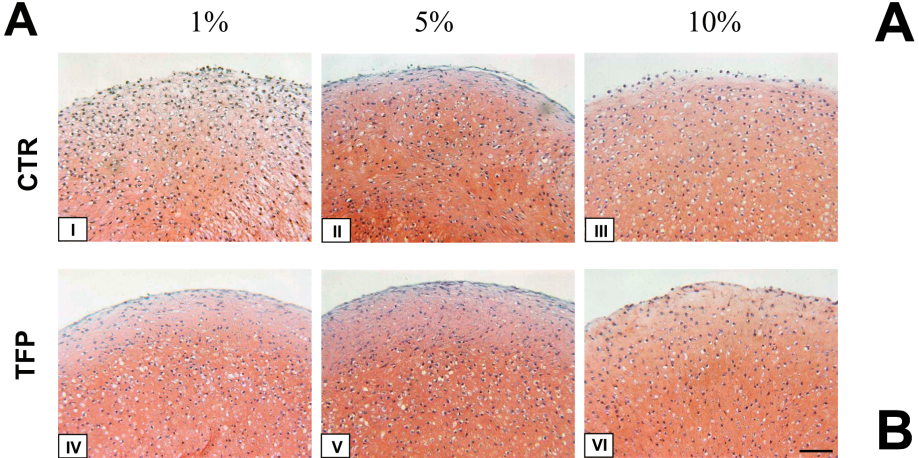

B

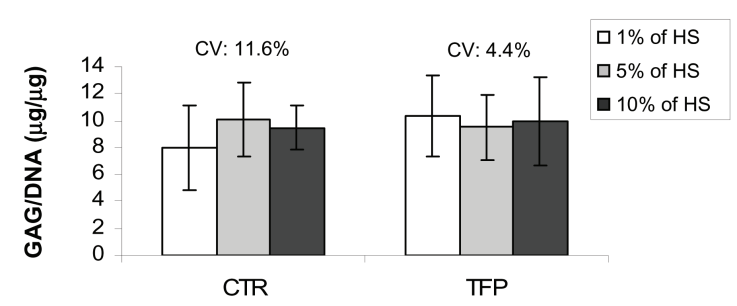

C

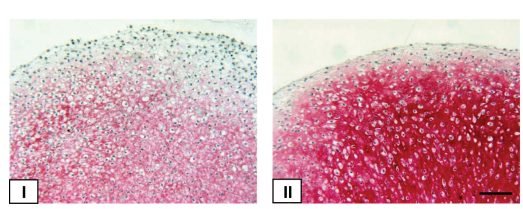

FIG. 3. Glycosaminoglycan (GAG) and collagen type II accumulation in pellets generated by human articular chondrocytes (HACs) after expansion with different percentages of human serum (HS). (A) Safranin O staining of representative pellets generated by HACs expanded with 1\% (I and IV), 5\% (II and V), or 10\% (III and VI) HS in medium without growth factors (CTR) (I, II, and III) or with transforming growth factor beta 1 , fibroblast growth factor 2, and platelet-derived growth factor type BB (TFP) (IV, V, and VI). Bar $=100 \mu \mathrm{m}$. (B) GAG content normalized to the amount of deoxyribonucleic acid (DNA) (GAG/DNA) in the pellets generated by HACs expanded under the different conditions. Results are means \pm standard deviations of values from 4 independent donor cell populations. Coefficients of variation (CVs) over each bar are the standard deviation (as \% of the mean) of the GAG contents measured at the different HS percentages. (C) Collagen type II immunohistochemistry staining of representative pellets generated by HACs expanded with $1 \%$ HS in CTR (I) or TFP medium (II). Bar = $100 \mu \mathrm{m}$. Color images available online at www.liebertpub.com/ten.

variability in proliferation rates of cells initially seeded at different densities. TFP-expanded chondrocytes generated pellets with high GAG contents even if they underwent a much larger number of doublings than cells expanded without growth factors. With the prospective of a clinical application, contact of human cells with FBS must be minimized, because proteins from ruminant materials have been implicated in prion transmission, ${ }^{22,23}$ and European legislation does not recommend their use. In the second part of our study, we therefore evaluated the effect of using HS on

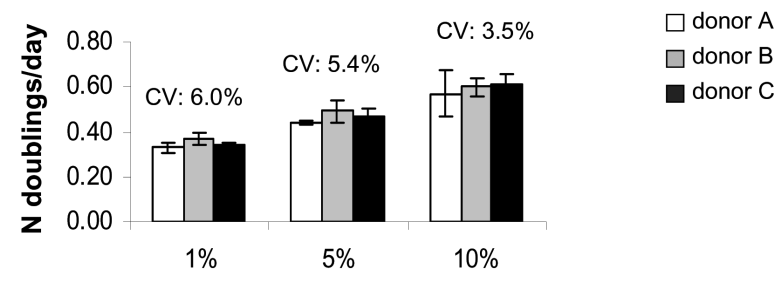

Percentage of human serum

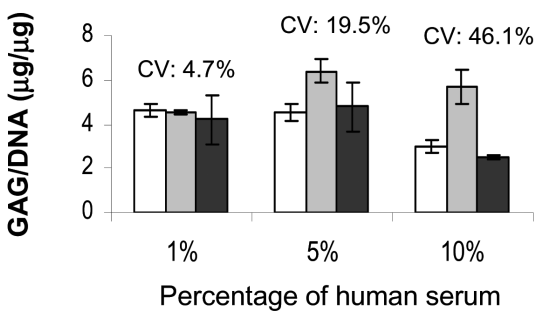

FIG. 4. Serum-related differences in the proliferation and glycosaminoglycan (GAG) accumulation of human articular chondrocytes (HACs). HACs from one cartilage biopsy were expanded in medium containing transforming growth factor beta 1, fibroblast growth factor 2, and platelet-derived growth factor type BB (TFP) and serum obtained from 3 different donors (A, B, and C) at increasing percentages. (A) Proliferation rates of HACs. (B) GAG contents of pellets generated by HACs. Coefficients of variation (CVs) over each bar are the standard deviations (as \% of the mean) of the proliferation rates or GAG contents of cells expanded with serum from the different donors.

HAC proliferation capacity. Our observation that $10 \%$ of a pool of HS supported higher proliferation of chondrocytes than $10 \%$ FBS is in agreement with previous results obtained using autologous $\mathrm{HS}^{24-26}$ and may be due to the higher concentration of epidermal-derived growth factor and PDGF measured in human serum. ${ }^{25}$ Using an initial cell seeding density of 10,000 cells $/ \mathrm{cm}^{2}$, we then showed that HAC expansion with TFP, but not with CTR medium, yielded more than 20 million cells for any HS percentage. Because the proliferation rate of HACs was higher using lower cellseeding densities (Table 1), it is likely that TFP will allow the required cell numbers to be obtained for any HS percentage even at the lowest seeding densities, although this remains to be experimentally determined. When HS from different donors was used, similar and low coefficients of variation in HAC proliferation rate were measured at any HS percentage, whereas coefficients of variation in the GAG content of resulting pellets were dramatically greater with HS percentage. This result confirms the importance of assessing not only chondrocyte yields but also their chondrogenic capacity and also indicates the need for a reduction in the percentage of HS used to increase reproducibility of HAC quality. In this context, the use of TFP during HAC expansion, by supporting sufficient cell yields even at low percentages of HS, could also contribute to reducing the variability 
in the number and quality of expanded autologous chondrocytes.

From a regulatory standpoint, the use of recombinant growth factors for the production of a therapeutic product requires the appropriate level of qualification. Safety concerns related to the use of TFP during HAC expansion should have minor relevance, because extensive washing of the cell preparation will remove these components so that they would be virtually absent in the final graft material. However, chondrocyte populations generated using TFP might need to be further analyzed for specific genetic alterations possibly related to senescence or DNA methylation before their clinical use.

In conclusion, our study showed that the use of TFP represents a viable solution for the reproducible and efficient clinical-scale expansion of HACs. Although our findings were based on the use of conventional tissue culture plates, implementation of the principle would be particularly relevant for automated processing systems for clinical use, which have higher constraints than typical manual culture in dishes. The concept of using specific growth factors in clinical-grade bioreactors could be applied for the propagation of cells from different human sources to reduce variability in the number and quality of expanded cells and, ultimately, in the clinical outcome of cell-based regenerative techniques.

\section{ACKNOWLEDGMENTS}

This work was partially funded by Millenium Biologix AG. We thank Ms Francine Wolf for her assistance in the immunohistochemical analysis.

\section{REFERENCES}

1. Brittberg, M., Lindahl, A., Nilsson, A., Ohlsson, C., Isaksson, O., and Peterson, L. Treatment of deep cartilage defects in the knee with autologous chondrocyte transplantation. N Engl J Med 331, 889, 1994.

2. Marcacci, M., Berruto, M., Brochetta, D., Delcogliano, A., Ghinelli, D., Gobbi, A., Kon, E., Pederzini, L., Rosa, D., Sacchetti, G., Stefani, G., and Zanasi, S. Articular cartilage engineering with Hyalograft C: 3 years clinical results. Clin Orthop Relat Res 435, 96, 2005.

3. Gobbi, A., Kon, E., Berruto, M., Francisco, R., Filardo, G., and Marcacci, M. Patellofemoral full-thickness chondral defects treated with Hyalograft-C: a clinical, arthroscopic, and histologic review. Am J Sports Med 10, 1, 2006.

4. Cherubino, P., Grassi, F.A., Bulgheroni, P., and Ronga, M. Autologous chondrocytes implantation using a bilayer collagen membrane: a preliminary report. J Orthop Surg 11, 10, 2003.

5. Bartlett, W., Skinner, J.A., Gooding, C.R., Carrington, R.W., Flanagan, A.M., Briggs, T.W., and Bentley, G. Autologous chondrocyte implantation versus matrix-induced autologous chondrocyte implantation for osteochondral defects of the knee: a prospective, randomised study. J Bone Joint Surg Br 87, 640, 2005.

6. Larcher, Y., Brunner, A., Sie, C.P., Tommasini, R., Smith, T., Oram, G., Misener, L., and Hagg, R. Advanced systems for clinical tissue engineering. Abstract presented at the 4th Symposium of the International Cartilage Repair Society (ICRS) Gent, 2004.

7. Peterson, L., Minas, T., Brittberg, M., Nilsson, A., SjogrenJansson, E., and Lindahl, A. Two- to 9-year outcome after autologous chondrocyte transplantation of the knee. Clin Orthop Relat Res 374, 212, 2000.

8. Barbero, A., Ploegert, S., Heberer, M., and Martin, I. Plasticity of clonal populations of dedifferentiated adult human articular chondrocytes. Arthritis Rheum 48, 1315, 2003.

9. Barbero, A., Palumberi, V., Wagner, B., Sader, R., Grote, M.J., and Martin, I. Experimental and mathematical study of the influence of growth factors on the growth kinetics of adult human articular chondrocytes. J Cell Physiol 204, 830, 2005.

10. Jakob, M., Demarteau, O., Schafer, D., Hintermann, B., Dick, W., Heberer, M., and Martin, I. Specific growth factors during the expansion and redifferentiation of adult human articular chondrocytes enhance chondrogenesis and cartilaginous tissue formation in vitro. J Cell Biochem 81, 368, 2001.

11. Johnstone, B., Hering, T.M., Caplan, A.I., Goldberg, V.M., and Yoo, J.U. In vitro chondrogenesis of bone marrow-derived mesenchymal progenitor cells. Exp Cell Res 238, 265, 1998.

12. Chaipinyo, K., Oakes, B.K., and Van Damme, M.P. The use of debrided human articular cartilage for autologous chondrocyte implantation: maintenance of chondrocyte differentiation and proliferation in type I collagen gels. J Orthop Res 22, 446, 2004.

13. Barbero, A., Grogan, S.P., Schafer, D., Heberer, M., MainilVarlet, P., and Martin, I. Age related changes in human articular chondrocyte yield, proliferation and post-expansion chondrogenic capacity. Osteoarthritis Cartilage 12, 476, 2004.

14. Brittberg, M., Peterson, L., Sjogren-Jansson, E., Tallheden, T., and Lindahl, A. Articular cartilage engineering with autologous chondrocyte transplantation. A review of recent developments. J Bone Joint Surg Am 85 (Suppl A), 109, 2003.

15. Melero-Martin, J.M., Dowling, M.A., Smith, M., and AlRubeai, M. Optimal in-vitro expansion of chondroprogenitor cells in monolayer culture. Biotechnol Bioeng 93, 519, 2006.

16. Grogan, S.P., Rieser, F., Winkelmann, V., Berardi, S., and Mainil-Varlet, P. A static, closed and scaffold-free bioreactor system that permits chondrogenesis in vitro. Osteoarthritis Cartilage 11, 403, 2003.

17. Hollander, A.P., Heathfield, T.F., Webber, C., Iwata, Y., Bourne, R., Rorabeck, C., and Poole, A.R. Increased damage to type II collagen in osteoarthritic articular cartilage detected by a new immunoassay. J Clin Invest 93, 1722, 1994.

18. Farndale, R.W., Buttle, D.J., and Barrett, A.J. Improved quantitation and discrimination of sulphated glycosaminoglycans by use of dimethylmethylene blue. Biochim Biophys Acta 883, 173, 1986.

19. Hicks, D.L., Sage, A.B., Schumacher, B.L., Sah, R.L., and Watson, D. Growth and phenotype of low-density nasal septal chondrocyte monolayers. Otolaryngol Head Neck Surg 133, 417, 2005.

20. Mandl, E.W., van der Veen, S.W., Verhaar, J.A., and van Osch, G.J. Multiplication of human chondrocytes with low 
seeding densities accelerates cell yield without losing redifferentiation capacity. Tissue Eng 10, 109, 2004.

21. Watt, F.M. Effect of seeding density on stability of the differentiated phenotype of pig articular chondrocytes in culture. J Cell Sci 89, 373, 1988.

22. Eloit, M. Risks of virus transmission associated with animal sera or substitutes and methods of control. Dev Biol Stand 99, 9, 1999.

23. Wessman, S.J., and Levings, R.L. Benefits and risks due to animal serum used in cell culture production. Dev Biol Stand 99, 3, 1999.

24. Gruber, R., Sittinger, M., and Bujia, J. [In vitro cultivation of human chondrocytes using autologous human serum supplemented culture medium: minimizing possible risk of infection with pathogens of prion diseases]. Laryngorhinootologie $\mathbf{7 5}$, 105, 1996.

25. Tallheden, T., van der Lee, J., Brantsing, C., Mansson, J.E., Sjogren-Jansson, E., and Lindahl, A. Human serum for culture of articular chondrocytes. Cell Transplant 14, 469, 2005.

26. Alexander, T.H., Sage, A.B., Schumacher, B.L., Sah, R.L., and Watson D. Human serum for engineering of human nasal septal cartilage. Otolaryngol Head Neck Surg 135, 397, 2006.

Address reprint requests to: Andrea Barbero, Ph.D.

Institute for Surgical Research \& Hospital Management

University Hospital Basel Hebelstrasse 20, ZLF, Room 403

4031 Basel Switzerland

E-mail: abarbero@uhbs.ch 